\title{
Processos de trabalho na saúde pública: humanização e efetivação do Sistema Único de Saúde
}

\author{
Work processes in public health: humanization and \\ fulfillment of Brazilian National Health System
}

\author{
Aline Morschel \\ Mestre em Psicologia Institucional. Psicóloga do Instituto Federal \\ do Espírito Santo. \\ Endereço: Rodovia BR IoI Norte, Km 58, Bairro Litorâneo, CEP 29932- \\ 540, São Mateus, ES, Brasil. \\ E-mail: alinemorscheløhotmail.com \\ Maria Elizabeth Barros de Barros \\ Pós-doutora em Saúde Pública. Professora Titular da Universidade \\ Federal do Espírito Santo. \\ Endereço: Av. Fernando Ferrari, s/n, Bairro Goiabeiras, CEP 29060- \\ 900, Vitória, ES, Brasil. \\ E-mail: betebarrosळuol.com.br
}

\section{Resumo}

0 presente artigo trata da temática "processos de trabalho no campo da saúde pública", tendo a Política Nacional de Humanização (PNH) e, mais especificamente, um curso de formação de apoiadores institucionais como referências. Por meio dessa atividade formativa e desde uma perspectiva cartográfica, foi composto um campo de pesquisa acompanhando/produzindo reflexões referentes ao modo como os processos de trabalho têm se realizado na saúde pública. Objetiva, assim, problematizar como a PNH tem comparecido nesse cenário, que questões têm sido levantadas, com quais impasses os trabalhadores se deparam em seu cotidiano do fazer-saúde, quais estratégias de enfrentamento têm sido disparadas. Parte do princípio de que os modos como os processos de trabalho são concebidos e realizados repercutem na produção de mudanças nas práticas de saúde e na efetivação do Sistema Único de Saúde (SUS) como política pública. Além do acompanhamento dos momentos presenciais do curso, foram realizadas entrevistas. Utilizou-se um roteiro de perguntas iniciais para disparar conversas com os trabalhadores formandos do curso e com formadores, estes últimos denominados "apoiadores pedagógicos”. Como resultados, obteve-se a problematização coletiva acerca do trabalho no contemporâneo e de importantes elementos que se presentificam no campo pesquisado, contribuindo assim para mudanças no cotidiano do fazer-saúde em que os trabalhadores estão inseridos, bem como ampliação dessa discussão no campo da saúde pública.

Palavras-chave: Trabalho; Humanização da Assistência; Saúde Pública. 


\section{Abstract}

This article deals with the theme 'work processes in the field of Public Health', using the National Humanization Policy (PNH) as a reference, as well as a training course for institutional supporters. Through this formative activity and from a cartographic perspective, a search field was composed, observing and producing reflections related to the way work processes have been conducted in Public Health. It aims to inquire how the PNH is seen in this scenario, what issues have been raised, which impasses workers have faced in their routine of working on health and what coping strategies have been deployed. The research assumes that the way work processes are designed and implemented has an impact producing changes in health practices and the effectiveness of Brazilian National Health System. Besides monitoring classroom activities, we also have conducted interviews with training workers and course instructors, triggered by a script of questions. As the result, we obtained a collective construction of questions regarding contemporary work and important elements that exist in the field of research, thus contributing to change the daily making of health in which workers are included, as well as amplificating this discussion in the field of Public Health.

Keywords: Work; Humanization of Assistance; Public Health.

\section{A pertinência da PNH nas políticas públicas em saúde}

A Política Nacional de Humanização (PNH) é uma política do Ministério da Saúde com frentes de trabalhos também nas esferas estadual e municipal. É pensada como estratégia para qualificação das ações de saúde e fortalecimento do Sistema Único de Saúde (SUS).

A temática da humanização na saúde se faz presente de modo mais sistemático desde 1999, quando algumas ações e programas começaram a ser pensados e implantados, a exemplo do Programa Nacional de Humanização da Atenção Hospitalar (PNHAH). Essas iniciativas, no entanto, se colocavam de modo ainda muito pontual, com ações fragmentadas e acabavam por se tornar fortemente ligadas a práticas voluntaristas e assistencialistas. Assim, pouco se colocava em xeque a(s) lógica(s) de produção de saúde que sustentava(m) as ações nesse campo (Benevides e Passos, 2005).

Em 2003, num cenário de mudança política, houve um investimento para que a humanização ${ }^{1}$ se configurasse não mais por meio de programas isolados, mas como uma política transversal, capaz de radicalizar discussões sobre a produção de saúde como bem comum, ou seja, como política pública. Partindo de experiências exitosas no campo da saúde - do "SUS que dá certo" - foi desenvolvido, então, todo um aporte teórico-conceitual e tecnologias pretendidas como fomentadoras de mudanças nas práticas de atenção e gestão da saúde e alinhadas aos princípios do SUS, a saber: universalidade, equidade e integralidade (Pasche, 2009). Chamamos atenção aqui para o termo "pretendidas", porque acreditamos que a efetivação dessa política se dá no cotidiano, em meio aos modos como ela é apreendida, apropriada e efetivada pelos trabalhadores e usuários de saúde.

Assim como a constitucionalidade do SUS não garante por si só a efetivação de seus princípios, a estruturação de uma política de humanização também não é suficiente por si mesma. Aliás, é preciso lembrar que se o SUS estivesse garantido por sua

1 A partir daqui utilizaremos diferentes nomes para falar da "Política Nacional de Humanização": PNH, "política de humanização", "humanização", "HumanizaSUS” e "política”. 
base legal a própria PNH, nessa sua proposta, seria desnecessária, visto que seu objetivo maior é o de concretização do próprio SUS. Com isso dizemos que "a” PNH só existe nos documentos que a especificam e, ainda assim, há de se observar o quanto mesmo dessa política "escrita" se modifica através de reformulações requisitadas e produzidas no cotidiano do fazer-saúde.

O que temos, então, por um lado, é uma política de humanização como o ofertamento de um instrumental composto por princípios, método, diretrizes e dispositivos, o qual acreditamos potente para disparar movimentos de construção da política pública de saúde brasileira. Por outro, circulam e se misturam vários sentidos, "políticas de humanização" se fazendo no cotidiano, produzindo práticas diversas que, inclusive, podem estar em descompasso com o próprio ideário da PNH. Pensamos que observar esse paradoxo e realizar essas críticas é pertinente e se faz não como quem desacredita nessa política, mas, ao contrário, para que o movimento na qual ela é pensada possa ter continuidade. Assim, pensamos que, mais do que afirmar o nome de uma política, o importante é fortalecer os movimentos inventivos de expansão da vida que se dão no cotidiano. Ressaltamos, então, a importância de tomar essas críticas como analisadores institucionais ${ }^{2}$ que nos permitam pensar o que, sob o signo da $\mathrm{PNH}$, se movimenta ou se paralisa.

A política de humanização tem disponibilizado uma série de dispositivos ${ }^{3}$ e investe num modo de fazer saúde apostando no fomento de grupalidades e inclusão dos diversos atores que compõem o cenário da saúde. Concebe, nesse modo de fazer, a inseparabilidade entre gestão e atenção, clínica e política, produção de conhecimento e mudança nas práticas (Brasil, 2008).
Desde a participação no programa de mestrado em psicologia institucional da UFES, na condição de orientadora e orientanda, pesquisamos como têm se dado os processos de trabalho na saúde pública: como o modo de organizar o trabalho repercute na atenção à saúde, na efetivação, ou não, dos princípios do SUS e na afirmação da dimensão pública de uma política de saúde. Partimos do entendimento de que os modos de gerir o trabalho e de produzir saúde são indissociáveis e que isso se dá concomitantemente à produção de subjetividade ${ }^{4}$ (Pasche, 2009).

\section{o locus de investigação, um duplo nó na PNH e a aposta na análise coletiva}

Para realização da pesquisa tomamos como locus de investigação o "Curso de formação de apoiadores institucionais" realizado pela Política Nacional de Humanização no estado do Espírito Santo, no ano de 2009, fruto de uma parceria entre o Ministério da Saúde (MS) e a Secretaria Estadual de Saúde (SESA). Configurou-se numa proposta de formação-intervenção que recebeu o nome de "Curso de formação em humanização para a atenção e gestão em saúde: construindo redes de produção de saúde", e visou formar 130 trabalhadores da rede de saúde do Estado para atuarem como multiplicadores da PNH em suas localidades de trabalho, na lógica do apoio institucional. Dessa forma, o curso colocou-se como um ofertamento tanto para qualificar/instrumentalizar os profissionais, no sentido de lidarem com as questões que enfrentam em seu cotidiano de fazer-saúde, quanto como uma estratégia de sustentabilidade da própria PNH, à medida que, por meio desses atores, temos aumentada a possibilidade de

\footnotetext{
2 Analisadores institucionais são acontecimentos que simplesmente irrompem em determinadas situações ou que podem ser forçados numa intervenção institucional e que colocam em xeque determinados modos de funcionamento, expondo as forças em jogo na composição de determinado campo. Segundo Rodrigues (2004), os analisadores “[...] catalisam ou precipitam (em um sentido quase químico) o que até então se encontrava disperso" (p. 148).

3 "Por dispositivos entende-se a atualização das diretrizes de uma política em arranjos de processos de trabalho. [...] são postos a funcionar nas práticas de produção de saúde, envolvendo coletivos e visando promover mudanças no modelo de atenção e de gestão” (Brasil, 20o8, p. 6).

4 A subjetividade entendida não a partir de uma origem, como algo interior ou imutável, mas o efeito de um campo heterogêneo de forças, constituídas por saberes, crenças, formas e instituições, ou seja, subjetividade como efeito de um campo de subjetivação. Trata-se de uma concepção heterogenética da subjetividade, na qual se dissocia radicalmente esta noção daquela de indivíduo. 0 indivíduo é, assim, pensado como uma das fomas-subjetividades produzidas historicamente. A subjetividade "[...] é essencialmente fabricada e modelada no registro social” (Guattari e Rolnik, 2005, p. 40), perfazendo uma produção.
} 
sua capilaridade na rede de saúde (Brasil, 2008).

0 curso foi realizado em nove módulos temáticos, com encontros mensais de um dia e meio, sendo o restante do último dia destinado à reunião interna dos apoiadores pedagógicos para avaliação do trabalho e reorientações de caminhos a partir do que se passava nos encontros. Intercalados a esses grandes encontros aconteceram também encontros menores, que duravam um dia e foram denominados de "dispersão". A dispersão se caracterizava pelos trabalhos com as unidades de produção (UP) ${ }^{5}$.

Por meio da pesquisa acompanhamos as atividades em diferentes momentos de encontro do curso. Nos momentos de dispersão optamos por acompanhar a UP da macrorregião centro, composta por trabalhadores de diversos serviços de saúde da Grande Vitória (Vitória, Cariacica, Serra e Vila Velha). Acreditamos que qualquer UP escolhida oportunizaria questões pertinentes, sendo a escolha motivada pela facilidade de acompanhar os trabalhos, tendo em vista que as dispersões dessa macrorregião se deram na Grande Vitória.

Nosso objetivo não foi o analisar o curso em si, mas, sim, nessa iniciativa de formação, pensar concepções e práticas de formação e de processo de trabalho em saúde, produzindo questões para o campo da saúde pública. Interessou-nos tomar o curso um dos "espaços" de encontros, trocas e produção de sentidos.

E por que pesquisar nesse curso da PNH? A PNH se coloca como uma proposta política interessante, alinhada às apostas desta pesquisa: uma dimensão ético-estético-política que vimos apontando em nosso texto. Tomá-la como locus de pesquisa está, então, na aposta de um espaço de provocações e problematizações acerca dos processos de formação e de trabalho no campo da saúde: o que entendemos por humano e o que queremos dizer quando falamos de práticas humanizadas? Esse tem sido um duplo nó na própria discussão sobre a PNH e implica enfrentamento de questões complexas.

Por um lado, coloca-se a urgência de se discutir a criação de outros modos de conviver, trabalhar, formar... Ser humano implica essa dimensão cons- titutiva, essa criação de possibilidades que nos permitem - e às vezes, diante do intolerável, nos forçam - nos reinventarmos. Trazer à cena essa discussão é, em última instância, o que nos moveu nesta pesquisa: uma ética vital de pôr em análise e reinventar! Acreditamos que uma política, ao trazer em seu nome "humanização", oportuniza esta discussão. Por outro lado, atentamos para os danos de se tomar "a" humanização sem esse movimento constitutivo, considerando-a como um título, uma qualificação ou denominação de práticas: "o serviço tal é humanizado", "nosso atendimento é humanizado", "precisamos humanizar esta unidade". Nessa perspectiva classificatória, temos uma humanização reiterando dicotomias que pretendemos superar: o certo e o errado; o bom e o ruim; o humanizado e o desumanizado.

\section{Instrumentos de produção de dados}

Utilizamos como instrumentos de produção de dados o diário de campo, a análise documental, entrevistas individuais e grupos de discussão, requisitados pelo próprio movimento de pesquisa.

O diário de campo é um registro gerado por meio de uma observação/participação nas atividades de formação e trabalho em todas as modalidades de encontro do curso. Além das informações objetivas dos acontecimentos, traz impressões, sensações, fragmentos de conversas, intensidades de vivências e interferências em nós de forças do campo.

As leituras e análises de documentos produziram-se nas atas de reuniões, memórias dos encontros, bem como no material de apoio ao desenvolvimento das ações pedagógicas do curso. No decorrer dos diferentes momentos de formação tornou-se imprescindível estar mais próximo e por mais tempo com alguns atores participantes do curso. Sentimos necessidade de desdobrar conversas sobre questões que se anunciavam nos espaços de participação em grupo, mas nem sempre ganhavam um corpo, uma textura mais evidenciada. $\mathrm{O}$ momento das entrevistas configurou-se, assim, como um tempo-duração de análise coletiva daquilo que estava sendo experimentado.

5 Como o curso envolveu trabalhadores da saúde de várias localidades do Estado, estas foram divididas três macrorregiões (macronorte, macrocentro e macrosul), nas quais foram formados subgrupos, as chamadas unidades de produção. 
O roteiro foi elaborado com questões que nos pareceram pertinentes às temáticas de formação e trabalho na saúde pública e sobre a PNH nesse contexto. Optamos por trabalhar com esse tipo de plano de questões por entendermos, desde uma perspectiva cartográfica, que o campo ao se fazer pode trazer questões importantes não antevistas pelo pesquisador e, assim, o roteiro porta uma abertura. Ao mesmo tempo, ele nos permite ter pontos de partida para desdobrar análises, assegurando a discussão de questões cruciais.

\section{O modo cartográfico de pesquisar e desdobramentos gerais da pesquisa}

Consoante à perspectiva cartográfica, buscamos compor com trabalhadores discussões que acionassem um movimento de análise de práticas de formação, de trabalho, de produção de saúde e de construção de políticas públicas no campo da saúde. Buscando indagar as noções que percebem o trabalho apenas como um ponto de incidência de forças de repetição do já estabelecido, procuramos evidenciar o labor como ponto de criação, de escapes, de invenção dos modos de trabalhar e de ser trabalhador. Procuramos, então, outros caminhos analíticos do trabalho em saúde, transversais àquelas linhas que tomam o trabalho como categoria abstrata, apenas alvo da exploração capitalista. Problematizamos análises funcionalistas que incidem na descrição específica da execução de tarefas, excluindo a dimensão de produção social que necessariamente inscreve o trabalho no curso de um tempo histórico e social.

Afirmamos a indissociabilidade entre os processos de trabalho e formação como uma aposta na invenção de problemas e a criação de outros possíveis no trabalho em saúde. Afirmamos o trabalho (de cuidado, de fala, de escuta, de escrita...) a um só espaço-tempo, como efeito, processo e produto de vida, constituído que é nas possibilidades e inventividades humanas.

Deleuze (1999), com auxílio de Henri Bergson, diz que o alcance de nossas respostas fala de como colocamos nossos problemas. Indagamos junto com os formandos e formadores entrevistados no curso: com quais questões temos nos deparado no nosso fazer cotidiano de saúde? Que problemas temos nos colocado? Que estratégias de enfrentamento utilizamos? A formação num curso sistematizado desestabiliza práticas naturalizadas no âmbito da saúde?

Acompanhamos um curso de formação que em seus movimentos se destacou pelas questões analisadoras surgidas nos espaços de discussão, pela constituição de grupalidade, pela produção de um modo de conceber e fazer formação (de ser formador, formando, pesquisador) em processo, pela criação de vias de passagem e expressão de algumas intensidades e, ainda, de silenciamentos e de interdição de outras intensidades.

Assim, na contramão de métodos de pesquisa em que a neutralidade se coloca como fundamento, entendemos que o ato de pesquisar se efetua sempre como interferência, fazendo parte da própria constituição do campo pesquisado (Kirst e col., 2003). Para além da afirmação de uma não neutralidade em pesquisa, a implicação das análises numa perspectiva cartográfica é que elas se criam em meio à experiência de pesquisa. Trata-se, aqui, de um processo de pesquisa junto aos trabalhadores - formandos e formadores -, catalisando discussões, acompanhando e problematizando deslocamentos nos caminhos de um curso.

A discussão acerca da criação de problemas nos ajudou a compor um plano de análise coletivo realizado junto a quem vivencia os dilemas cotidianos, diferenciando-se, dessa forma, das perspectivas baseadas no binômio diagnóstico-solução realizado por equipes de especialistas externos por meio de análises pontuais. Nossa aposta na colocação de problemas não coincide com a simples constatação de algo que "anda errado" e que, portanto, deve ser "ajustado". Colocar um problema é, antes, sair da esfera dos problemas dados, nos convocando a lançar nosso olhar para as próprias condições de constituição de uma dada situação, da possibilidade de sua emergência enquanto tal.

Foucault (2005), em referência a Canguilhem, indaga: aquilo que tão facilmente temos tentado rechaçar, aquilo que se coloca como algo a ser eliminado - o erro - não seria algo através do qual a vida se afirma? Erro marcado não pelo descompasso entre 
aquilo que deveria ser e o que não é, como equívoco fatal, mas como aquilo que perturba o sistema vivo, forçando-o a se reinventar: "[...] o erro é a contingência permanente em torno da qual se desenrola a história da vida e o futuro dos homens" (p. 365).

Não se trata aqui de uma simples diferença de compreensão em torno da temática do erro. Provocamos, sim, uma alteridade num terreno em que a produção de conhecimento, ao ser entendida como descoberta de verdades, estabelecimento de leis universais, coloca tudo o que não cabe nesses esquemas invariantes em um plano de falsidade, desvio ou falha. 0 erro é, assim, negativado. A esse modo de produção de saber concorrem práticas de correções, adaptações e ajustes, e todo um aparato técnico se constrói ao mesmo tempo em que lhe dá sustentabilidade. Surge todo um sistema de valoração que marca o certo e o errado, o verdadeiro e o falso e que tem no estabelecimento da norma seu referencial: sistemas binários que sufocam e até inviabilizam traçados divergentes e constrangem a própria vida, pois, "[...] no limite, a vida - daí seu caráter radical - é o que é capaz de erro" (Foucault, 2005, p. 364).

No tocante ao nosso campo temos que a insatisfação dos profissionais, o alto índice de adoecimento e de "descomprometimento" no trabalho não falam somente da insuficiência das soluções pontuais - geralmente vindas em pacotes formatados ${ }^{6}$-, mas, principalmente, do modo como os problemas frequentemente são concebidos e colocados. Essa problemática, que já se anunciava em nossa inserção prévia no campo da saúde pública, foi fortalecendo nossa aposta em interrogar esse cotidiano de saberes e fazeres. Isso era imprescindível para operar outras maneiras de habitá-lo, permitindo desfazer a produção de adoecimentos e apatias geradas em torno da falta de perspectivas de modificação do que se encontra cristalizado.

Sair dos "problemas" evidentes é efetuar uma problematização mais radical, que indaga o que temos feitos de nós mesmos, que forças compõem os cenários nos quais atuamos e de que forças dispomos para operar um modo mais condizente com a afirmação da vida: sua potência errante. Colocar problemas é não conformar-se com os problemas dados e suspeitar das evidências, das formas e do instituído. Suspeitar não desacreditando de sua existência, mas acreditando que sua existência não é essencial, e, sim, contingente: desnaturalizar a realidade, estranhar o que parece óbvio, irreversível, imutável.

Para além dos problemas a serem revolvidos, a potência dos enfrentamentos estava na sua dimensão constitutiva, ou seja, no plano de produção. A perspectiva institucionalista ${ }^{7}$ nesta empreitada, ao invés de diagnósticos prontos e prescrições, indaga como, por meio de conceitos-operadores ${ }^{8}$, acionar uma "perguntação" que desmonte certezas, criando outros mundos e sujeitos possíveis.

Assim, ao compor um campo de pesquisa não nos interessou julgar, marcar o certo e o errado, identificar sujeitos ou encontrar causas, localizar os problemas num determinado lugar, num cargo ou numa pessoalidade. Esses, para nós, são falsos problema ${ }^{9}$ no sentido bergsoniano, à medida que tomados como questões prontas acabam por dificultar o acesso à dimensão processual dessas visibilidades, inviabilizando interferências que incidam nas condições de sua emergência.

6 É relevante, nesse sentido, a grande quantidade de cursos de capacitação e implantação de programas que, sem considerar a complexidade das realidades locais, pautam-se na aplicabilidade de técnicas. Muitas vezes essas ações acabam se constituindo como um tarefismo que, longe de instrumentalizar os trabalhadores a lidar com suas questões, acaba se colocando como mais um elemento que esses precisam dar conta.

7 Sob perspectiva ou movimento institucionalista se designa uma diversidade de produções teóricas e práticas de intervenção que guardam em comum, como nos diz Rodrigues (2004), a problematização do real, daquilo que corriqueiramente é tomado como pronto e acabado. É importante ressaltar que também compõe esse campo a "filosofia da diferença" ou "pensamento da multiplicidade" tendo como principais autores Félix Guattari, Gilles Deleuze e Michel Foucault.

8 Chamamos de conceitos-operadores aqueles que funcionam como dispositivos, ou seja, que nos ajudam a pôr em análise coletivamente algo ou determinada situação. Em consonância com Lourau (1993), pensamos a potência dos conceitos, tanto de sua criação quanto de sua utilização, a partir da necessidade surgida no próprio ato de pesquisar. Assim, é a pesquisa que requisita os conceitos e não o inverso.

9 Para maior detalhamento sobre a ideia de falso problema em Bergson recomendamos a leitura do capítulo "A intuição como método" da obra Bergsonismo, de Deleuze (1999). 
O que balizou nossa pesquisa, assim, foi a aposta em colocar em discussão elementos que nos pareciam essenciais para fazer frente aos constrangimentos da vida na contemporaneidade, foi o acreditar na construção de modos mais solidários de convivência, relações menos verticalizadas nos processos de trabalho. Acreditamos que pensar essas questões é também assumir um compromisso com a afirmação de uma política de saúde que se efetive como pública, ou seja, uma política capaz não apenas de atender as necessidades de saúde de "todos e qualquer um", mas que ganhe sustentabilidade por meio de movimentos que ultrapassem as políticas de um governo (Benevides e Passos, 2005).

\section{Nosso trabalho acerca do trabalho: reinvenções e produção de saúde}

O que indaga o ingênuo e potente diálogo: o trabalho é necessariamente sofrimento? É possível fazer do trabalho algo que não apenas fonte de reclamação e desprazer? 0 que faz no contemporâneo o trabalho ser tão sofrido? O que faz com que, apesar do sofrimento e para além da simples sobrevivência, o trabalhador continue a se dedicar às ações de trabalho?

Antes de abordarmos propriamente os dados da pesquisa que oportunizou este artigo, ressaltamos mais uma vez que nosso interesse aqui é o de utilizar a experiência de acompanhamento do curso de formação para problematizar práticas e saberes e compor um campo de análise em saúde pública.

Nesse campo nos deparamos frequentemente com frases de trabalhadores e situações que indagam: "Como se cuida de alguém quando se sente descuidado? Como se produz saúde num labor que produze adoecimento? Como oferecer um atendimento (cuidado) humanizado sem a humanização se fazer nas condições e relações de trabalho?"

O trabalho, o trabalhar, sendo uma ação transformadora, tem sido tratado/analisado de diferentes modos. É preciso observar, no entanto, que não apenas as formas de tematização divergem, mas a experiência de trabalho vai se modificando ao longo dos tempos - as formas de trabalhar, sua conceituação, as formas de remuneração e os sentidos que assume. Tomamos o trabalho como um vetor complexo que nos exige analisá-lo de acordo com o que em nosso tempo o presentifica, um misto que assume diferentes intensidades, nuances, formas, lógicas... a partir das transformações sociais que o interpelam.

Dizer que o trabalho nem sempre foi o mesmo não é marcar uma evolução progressiva do que seria um trabalho substantivado, mas afirmar, ao contrário do que se quer numa perspectiva representacional da realidade, a dimensão ontológica da experiência de trabalho, a partir da qual coemergem trabalho e trabalhador. Nem sempre tivemos trabalho assalariado, nem emprego formal, nem garantias trabalhistas, nem tecnologias associadas, como o uso de máquinas e produtos químicos. Nem sempre foi possível - e, ainda hoje, em determinados lugares não o é - a mulher exercer determinadas ações laborais; nem sempre, e nem em todos os lugares, temos a convicção de que o trabalho infantil e/ou escravo deva ser erradicado. Divergem, ainda, os recursos e as aptidões tidas como necessárias para realização de determinados trabalhos, bem como as formações e os efeitos envolvidos.

Coletivamente passamos a poder dizer que os atores (que "fazem") exigem cuidados, que há um processo saúde-doença e que há doenças e agravos relacionados ao trabalho. Construímos instrumentos de fortalecimento dos processos de saúde e lutas sociais diretamente ligadas ao labor ${ }^{10}$ proliferam-se e acirram o jogo de forças... Junto com alguns autores (Barros e Benevides, 2007; Fonseca e Barros, 2010) partimos de um entendimento de trabalho como processo configurado contingencialmente, uma prática de transformação em que se realiza, a um só tempo, a produção de objetos (físicos utensílios, carros, livros - e não-físicos - cuidado em saúde, conhecimento, práticas de formação) e a

10 Lutas por trabalho digno (melhores condições de trabalho e salário, redução de carga horária sem redução de salário), pela ampliação de concursos públicos, pelo reconhecimento de algumas atividades (a exemplo das(os) profissionais do sexo), o reconhecimento jurídico de práticas desrespeitosas (assédio moral, constrangimentos), reconhecimento de elementos psíquicos, emocionais e relacionais no estabelecimento de nexos causais entre determinados agravos/doenças e certas atividades laborais), lutas por maior participação dos trabalhadores em decisões relacionadas ao coletivo, dentre outras. 
produção de subjetividade (modos de trabalhar, de se relacionar, de resistir a adoecimentos, de pensar, sentir e viver).

Acreditamos que nossa pesquisa foi instrumento de fortalecimento de análises locais sobre os processos de trabalho em curso: colaborou em fazer saltar de uma aparentemente homogeneidade - evolução progressiva, intervenção sobre a realidade num sentido adaptativo - a heterogênese própria do plano constitutivo das formas, as irregularidades e as rupturas que inscrevem no trabalho seu sentido de acontecimento ${ }^{11}$ e fabricação própria do real.

Distanciamo-nos das noções que tomam o trabalhador como vítima do capitalismo. Acompanhamos Hardt e Negri (2005) na afirmativa de que a mudança de configuração do mundo do trabalho e das formas de investimento sobre ele também acenam para mudanças nas lutas nesse campo. Com a crescente diversificação de atividades e emergências de diferentes modalidades de trabalho imaterial, a dimensão repetitiva, mecanicista do trabalho, convive com explorações que adentram o tempo, o pensar e desejo do trabalhador, sem que a lógica hegemônica liberal-privatista seja necessariamente desmontada. O investimento no "fator humano", na produção de afetos e na dinamicidade na esfera produtiva se realiza num contexto onde o poder exercido se destinará não à circunscrição de forças, mas à sua devida administração, direcionando-as para a finalidade de manutenção da produção hegemônica. Trata-se da realização do biopoder numa exacerbação da globalização, pretensamente eterna, ramificada, na intimidade: "Império".

Em nossa pesquisa nos deparamos com questões levantadas pelos trabalhadores e que geralmente são imperceptíveis ou mesmo ignoradas quando o trabalho é avaliado: mudanças de paisagens nas cidades do interior do estado do Espírito Santo e nos grandes centros, o trabalho em turnos, em que a possibilidade de realização das atividades se faz de modo diferenciado, são um dos fatores das condições de trabalho que desmancham análises que recaem sobre o indivíduo:
Trabalhar como médico de família é sempre num lugar mais violento [...] e exigem da gente como se isso não fizesse parte da paisagem [...] A gente entra, começa a trabalhar e não sabe nem, exatamente nem... nem é apresentado pras pessoas que a gente vai trabalhar junto... (trabalhador-formador).

A gente entra e sai e não se integra nem mesmo com os outros colegas do plantão. A gente chega, o quadro de funcionários também é menor, à noite tem menos pessoas [...], então a gente trabalha mais, ainda tem o horário de descanso que a gente prioriza, então a gente quase não se comunica mesmo entre a gente [...] Às vezes a enfermeira passa, conversa essas coisas mas só que é assim... diferente do dia (trabalhadora-formanda).

Ao mesmo tempo, os trabalhadores nos dizem de algumas estratégias inventadas para lidar com impasses, num movimento nada passivo; positivo, de alianças:

[...] não é abrir mão de uma luta por garantia de melhores condições de trabalho, mas é também não se paralisar por não ter as condições ideais (trabalhador-formando).

Assim, vemos surgir a tessitura de uma rede de solidariedade, de fomento de saúde, produção de parcerias como as descritas a seguir por uma formanda trabalhadora de um hospital, ao falar do modo como tentam encaminhar o problema da diferenciação nas formas de contratação dos profissionais de saúde:

Ai a gente treina, treina, treina, quando a menina está boa, aínós mesmos arrumamos empregos pra elas lá fora. Nós mesmos arrumamos! Cansamos de arrumar! Tem uma lá mesmo agora... [...] a gente acha injusto elas ganharem um terço do que a gente ganha e fazer o mesmo serviço [...] se ela é boa e aguenta, a gente mesmo arruma pra elas em outros hospitais (trabalhadora-formanda).

Vivenciamos um curso de formação-intervenção que possibilitou a articulação da rede local de saúde, desde os primeiros encontros em que para as formações das UP os participantes assumiram

11 Aqui tomamos por influência o conceito de acontecimento em Foucault trabalhado por Revel (2005), que nos diz do acontecimento como a “irrupção de uma singularidade". Para nós, então, a acontecimento é a marca de uma transformação qualitativa, gestada, não evolutiva, não sequencial, mas, sim, uma composição imprevisível, um resultado sempre provisório decorrente de um campo de forças. 
uma postura ativa, propondo a alteração da configuração inicial dos grupos previstos por sua equipe organizadora. Para tal, os formandos analisaram criticamente a organização por distância física dos serviços e colocaram em cena o critério de maior interface entre eles.

Curso que serviu para ampliar a percepção e a sensibilidade e fazer com que não mais se pudesse passar por determinadas situações sem estranhá-las:

[...] e eu nunca saio da sala, mas hoje eu saí com a cabeça cheia, pensando nas leituras. $\mathcal{E}$, ai, eu vou entrando lá pro nosso escritório e eu vejo uma mãe sentada perto da nebulização, com um bebê no braço; e o bebê é especial, tem algum déficit neurológico, não sei bem o quê. Aí eu entrei e fiquei pensando: "gente, será que essa mãe acompanha esse menino na APAE? Será que ela sabe da questão da estimulação precoce? Esse menino pode ser estimulado! Será que ela faz alguma coisa? Será que ela tem alguma informação?" E fui lá e peguei um copo pra tomar um café [...] sabe, mas essa coisa me incomodando. Ai pensei: "espera lá, eu acabei de ver uma coisa na qual eu posso intervir, está ao meu alcance de intervir, de fazer uma diferença e eu 'tô' aqui tomando um cafezinho?" Sabe, isso me incomodou a tal ponto... não, eu fui lá! [...] Do ladinho dela tava vazio, ai eu sentei. No que eu sentei e comecei a bater papo com ela, ao invés de ensinar pra ela eu comecei a bater papo e trocar informação com ela. Eu senti o mundo se abrindo nessa hora... (trabalhador-formando, grifos nossos).

Curso como construção de um território possível, antes tido como "utópico" pejorativamente, apropriado como "caixa de ferramentas" de uma política de saúde mais próxima ao sonho, ao desejo, aos princípios, ao fazer junto.

[...] A gente já faz muito, mas eu quero fazer do SUS aquilo que ele nasceu pra ser aqui dentro (do serviço). E a diferença é que agora eu tenho instrumentos, eu tenho como fazer isso, o curso me deu! [...] a gente "tá" chamando eles (trabalhadores da unidade) pra decidir junto "Vem cá, não está legal assim, o que a gente pode fazer?" [...] chamar todo mundo, fazer uma pauta, enfim... de começar a discutir junto essas coisinhas do meu trabalho que "interfere" no seu e que a gente não senta pra dizer assim: "Ah, vamos fazer como então?" (trabalhadora-formanda).
Curso em que um dispositivo do acolhimento com classificação de risco (ACCR) é barrado, não pela falta de desejo em fazê-lo acontecer, e, sim, como resistência ativa dos trabalhadores em "implantar" algo sem uma discussão ampla e prévia, sem a criação das condições necessárias para que de fato ele pudesse dispor um cuidado mais qualificado.

[...] começou a discussão da questão do ACCR. Começou a 'vim' gente aqui pra ver o que ia fazer, o que ia precisar e tal. E eu "tava" de plantão e vendo as coisas acontecerem: "-Ah, eles querem começar acolhimento com classificação de risco pra ontem aqui e tão vendo o que é que vão precisar e tal; como é que vai ser, quando é que vão começar..." Até que um belo dia a diretora falou: "Ah, vamos reunir aqui, todo mundo vai estar aqui, o pessoal do Estado... sobe uma de vocês aí pra gente começar a discutir alguma coisa". Ai eu disse: "Colega, eu estou participando do curso da PNH, deixa eu subir, você fica aí no plantão". Então foi quando a gente falou: "Não, não dá pra fazer assim" [...] não dá pra trabalhar a classificação de risco se a gente ainda não tem como garantir o acolhimento, se não vira simplesmente uma triagem, sem nem mesmo ter os instrumentos e sem entender direito: "O que é isso, né?!" Aífoi quando eu disse: "Gente, isso faz parte de uma política! Isso não é bem assim!” $\varepsilon$ aí conseguimos impedir da coisa vir de cima para baixo (trabalhadora-formadora).

As conversas também renderam reflexões sobre a humanização na saúde: A humanização está para muito além de pintar parede e ser simpático, nos diz uma trabalhadora-formanda.

Perguntas importantes surgiram na intensidade dos encontros, das discussões oportunizadas por estar junto, pelo tempo de "parada” para pensar o que fazemos, como fazemos e quais efeitos daquilo que fazemos. Assunto dos momentos: constituição de grupalidade:

[...] eu acho que a gente tem que se habituar a se construir enquanto coletivo, em primeiro lugar. Você não tem como avaliar a questão do curso sem levar em consideração quantas outras oportunidades de fomento de grupalidade a gente tem? Então, eu acho [...] que talvez algumas coisas precisem ser construídas e encaminhadas de forma diferente, não [...] por conta da proposta do curso em si, mas por uma 
necessidade que a gente tem de desenvolver e trabalhar na grupalidade. Não sei se vocês observaram, mas me chamou atenção o número significativo de propostas que vêm sendo apresentadas como intervenção no curso em torno de construir rodas... (trabalhador-formando).

Numa outra fala um trabalhador-formador evidencia que o grande mote talvez não esteja em dirimir os problemas, desejar simplesmente encontrar soluções para que eles não mais existam, mas garantir a legitimidade do espaço de discussão coletiva:

Aí eu fiquei pensando depois: "mas é isso!" Não é a solução do problema, mas o espaço garantido para discutir. Então eu falei... até não sei se copiei de alguém, mas vi o nome: "espaço de pactuação permanente". Aquilo era garantido e era vital para o grupo.

Muitas vezes os problemas são pensados e encaminhados na lógica da sua solução, gerenciamento/ administração, ao invés de sua colocação e da gestão coletiva.

Quem sabe resolver o problema é o cara que consegue gerenciar... é o enfermeiro gerente. É o cara que tanto gerencia processos, gerencia pessoas, gerencia conflitos. Esse cara com uma cabeça...você pode pegar esse cara, tirar esse cara da enfermaria do hospital e colocar ele na frente de uma empresa, ele sabe administrar uma empresa. É o enfermeiro administrador (trabalhador-formando).

Vimos também trabalhadores, ao falar da história de sua profissão - a enfermagem -, indagarem a provisoriedade das soluções que, ao serem institucionalizadas e "tornadas naturais", enrijecem o corpo e o pensamento para o devir, para o atual de nosso cotidiano.

Tudo bem, só que... isso ficou normatizado e pronto, agora não estamos no tempo de guerra e isso é tido como o correto. Os hospitais de agora em diante vão se organizar dessa forma que a gente viu que fica legal assim, e parou no tempo. E agora? Será que hoje a gente não pode parar e repensar isso? Será que não surgiram... será que a gente não detecta outras necessidades? Porque essas do tempo da guerra ${ }^{12}$ a gente já conseguiu equalizar. $E$ agora? A gente tem feito muito pouco isso... (trabalhador-formando).

Sentir-se participante de um coletivo que, ao se organizar, conquista autonomia, amplia o poder de decisão e traz outra perspectiva do que é ser trabalhador da saúde, de como estamos implicados necessariamente nos acontecimentos e qual a responsabilidade que assumimos:

[...] quanto mais você sabe, quanto mais consciente você se torna, mais você se inquieta, mais você é cobrado, mais você se sente corresponsável pelo processo, mais você "se" atenta para uma reflexão maior, mas você consegue enxergar as consequências, os riscos. Mas também eu acho assim que, como eu disse anteriormente, traz algumas ofertas e algumas ferramentas para gente. Ao mesmo tempo em que você se sente mais cobrado e responsável, quando você faz parte de uma proposta de um coletivo, você não se sente mais tão impotente e tão sozinho (trabalhadora-formanda).

No dia de abertura do curso um trabalhador, ao final da apresentação, fez uma indagação-indignada que é ao mesmo tempo um pedido:

Será que neste curso haverá de fato uma mudança na lógica de formação ou terão sido apenas palavras bonitas que ao final apenas repetem modos formativos com nova roupagem?

Outra questão referente às ações de formação em saúde pode ser vista na seguinte passagem, que nos impele a pensar os efeitos correlatos à forma segmentada como geralmente elas vêm acontecendo e que serve de alerta à própria $\mathrm{PNH}$ :

[...] uma das maneiras de não dar certo (as formações) é chamar as pessoas a todo o momento para se capacitar. Então, vem a tuberculose, vem a hanseníase, vem a hipertensão, aids, DST e vem a humanização e "tira" as pessoas das unidades. Então, nós precisamos convergir pra concentrar as ações e aívamos ter que pendurar os egos das políticas e dizer assim: "não, tem um dia que as pessoas se reúnem em roda pra discutir suas questões”. E ai

12 Referência às guerras da Crimeia e do Paraguai, em que Florence Nigthingale e Ana Néri, respectivamente, contribuíram com a implantação e organização de procedimentos de cuidado em saúde aos feridos. 
nós vamos ter que legitimar isso aí. $\varepsilon$ ai, assim, eu não sei como vai ser, mas precisa de alguém para acompanhar. A gente vem discutindo muito isso, mas não tem receita pronta (trabalhador-formador).

No âmbito dos processos de trabalho, Merhy (2002) dispõe a ideia de que sua especificidade se dá em não podermos eliminar o trabalho vivo em ato. Apesar da lógica de distanciamento entre pensar e executar - marcadamente predominante no modo de produção capitalista - perpassar o campo da saúde, principalmente na formação profissional, ela não impera no cotidiano das práticas. Esse autor aponta duas questões importantes: a produção de cuidado em saúde se dá no mesmo instante do seu consumo e, consequentemente, esse cuidado se dará sempre na relação. E, sendo a relação produção em ato, será nesse contato vivo e inusitado com o outro que ocorrerão transformações. 0 trabalho em saúde pressupõe, assim, lidar com o imprevisto, com o inusitado, requisitando inventividade e improviso por parte dos profissionais, num processo que "[...] não pode ser globalmente capturado pela lógica do trabalho morto [...] processo de intervenção em ato, operando como tecnologias de relação, de encontro de subjetividades" (Merhy e col., 2002, p. 121).

O trabalho aí se anuncia como uma zona estratégica para as mudanças que se anunciam no campo da saúde pública, pois é aí que se pode evidenciar o confronto das diferentes lógicas de produção de bens, serviços, modos de subjetivação e de organização social.

O profissional da saúde pública vive, assim, neste campo de tensões em que uma formação profissional tecnicista se mostra insuficiente para efetivar o projeto de democratização da saúde desejado desde os primeiros movimentos populares e na criação do SUS. Há uma luta contínua engendrada por diferentes projetos de saúde: forças liberal-privatistas e forças afirmativas da dimensão pública de uma política. Vejamos uma intervenção de um trabalhador-formador falando-nos não apenas sobre a PNH como política pública:

[...] não é humanização em si, mas o que está em jogo é (a) vida das pessoas, são opções de vida que se vai fazer que a humanização pode despertar. Uma nova maneira de você trabalhar, uma nova maneira de vocêviver. Então, talvez... a política "serve" pra isso, pra você viver melhor. Eu acho que a política tem que estar a serviço do ser humano, não o contrário (trabalhador-formador).

Campos (1997) considera que poucos estudiosos dedicam-se a pensar estratégias de construção de algo diferente. Segundo o autor "[...] se, por um lado as coisas, ou as estruturas, determinam a vida das pessoas, por outro, são estas mesmas pessoas que constroem as coisas, as normas, os valores e as estruturas" (p. 30). É preciso olhar sim a cronicidade dos serviços e das posturas de profissionais, mas é preciso também concretizar outros modos de fazer saúde, novas estratégias para o seu funcionamento. Nesse sentido, um dos trabalhadores-formandos entrevistados nos relata a importância do referencial da PNH para permitir ultrapassar as queixas e até mesmo os diagnósticos e já no próprio "cursar do curso" produzir e sentir as interferências - apontando essa característica como um dos grandes diferenciais do curso em relação a outras atividades de formação de que já havia participado no campo da saúde.

Alguns autores (Merhy, 2002; Merhy e col., 2002; Campos, 1997, 2000; Passos e Benevides, 2004) têm partilhado a perspectiva institucionalista ao conceber a ideia de que, para se disparar um processo de diferenciação do que se encontra instituído em práticas convencionais, é importante fomentar um olhar ético-político interrogador por parte dos próprios sujeitos que compõem determinado campo. 0 movimento capaz de produzir deslocamentos talvez se insinue mais na problematização e nos arranjos compostos local e coletivamente do que necessariamente num espaço de autonomia que seja ofertado. "Dar a voz", "empoderar”, "conscientizar”, "dar liberdade" aos profissionais nos soam, dessa forma, como questões insuficientes e até mesmo equivocadas.

A política nacional de humanização inscreve em seus documentos e instrumentos formativos o processo de trabalho como a matéria-prima para se analisar os processos de produção de saúde (Brasil, 2008). Tomando como inseparáveis os modos de cuidar e de gestão, aponta também a inseparabilidade entre clínica e política e nos diz que é no próprio caminhar que as questões surgem, forçando a invenção de novas estratégias e formas de atuar no cotidiano. Para nós, os documentos orientadores dessa política 
têm grande importância no fomento de discussões que coloquem em xeque modos naturalizados de trabalhar e ser trabalhador: desde a perspectiva que constitui a PNH, humanizar é analisar processos de trabalho.

Os desejos de integração, de pensar junto, de compartilhar, todo esse processo que pode ser gerador de saúde e que geralmente é esfriado nos processos prescritos de trabalho, encontram ressonância nos movimentos correlacionados ao curso da $\mathrm{PNH}$, nos dispositivos ofertados pela mesma. Ainda que essa afirmativa não seja uma defesa da política por ela mesma e todo seu conjunto atual, é uma constatação de que esse conjunto, com todas suas potencialidades e contradições, prevê uma apropriação, uma construção a ser feita, uma obra aberta; prevê, enfim, autogestões de coletivos.

Eu vejo assim: não sei se é o momento que a gente tá vivendo lá no centro cirúrgico, que é o meu ambiente, mas eu vejo que há uma sede, uma necessidade muito grande de que alguma coisa seja feita, sabe? Não só em questão de mudança com o paciente, mas em mudança com o grupo mesmo, sabe?! De você unir, de ligar por alguma coisa, de reivindicar alguma coisa. Eu senti que o processo de trabalho do jeito que "tá" não dá pra continuar [...] a gente "tava" conversando sobre trabalho, sobre processo de trabalho, ai uma colega que tá fazendo um dos cursos "tava" falando que vai ter uma intervenção, vão ter que fazer e perguntou o quê que eu achava, o quê que eu pensava. Eu falei: "É processo de trabalho!" (trabalhadora-formanda).

Há muitas falas que acenam para a criação de um campo de ressonâncias alegres, afirmativas, mesmo em meio a tantas dificuldades, sentidas pelo trabalhador no cotidiano do fazer-saúde, em perceber o vital no processo de trabalho, sua potência criadora:

Então, assim, tem esse lado meio doído, né? Que eu entendo, mas... tem um lado ultra prazeroso, você ir pro interior e ver gente que... "tá" na mesma lenha que você, "tá" a fim de fazer. Então, eu acho que o curso reacende algumas coisas que eu acreditava, nessa coisa de constituir, de não ter uma formalidade, mas ter um embasamento [...] ter consistência nas ações. Não ficar imobilizado porque não tem as condições ideais. Correr atrás e continuar ba- talhando com ofício, com papel, mas você "tá" ali fazendo, estudando e motivado pra estudar. Vários, vários exemplos. Esse do HEMOES (Hemocentro do Espírito Santo) então foi fantástico! O cara do HEMOES de São Mateus pegava e ia localizar a cidade, criar um espaço em cada município para coletar sangue. $́$ comovente isso que eles fizeram. Você imagina, o sujeito que queria doar sangue, ele tinha que sair da cidade dele pra doar, ir lá em São Mateus, andar quilômetros. Aí eles vão, criam um espaço ali, o município faz a fiscalização: "Aonde que vai coletar o sangue? É aqui?”; montam lá, fazem uma estrutura pra coletar sangue daquelas pessoas sob supervisão. Fora outras assim. Eu "tô" dando o exemplo porque foi uma coisa que eles falaram pra gente assim: "Oh, a gente queria fazer isso, $o$ curso deu elementos pra gente fazer". Então é isso... eles poderiam ficar esperando com ofício: "Oh, a gente quer mais funcionários". Mas eles viram que a situação é a seguinte: o sujeito vai doar e não é acolhido. Normalmente vai tirar alguma coisa, um exame, um remédio, um atendimento, uma consulta. Não, esse vai doar! É aí inversão do usuário, esse não é usuário, é "ofertário", sei lá o nome que é. Aí eles captam isso, que o sujeito vai lá ofertar, mas ele precisa de condição para isso. A condição é ir lá perto da casa dele. Não é porque o HEMOES, um órgão central, pesado, mastodôntico, que ele tá imobilizado. Então, é isso aí! Ah, isso me deixa empolgado! Vou terminar meu ano feliz [...] Saiu na Gazeta (A Gazeta, jornal impresso do estado do Espírito Santo) essa história deles, fez aquele barulho, saiu no jornal. Aí, engraçado que foram lá entrevistar eles e eles não estavam lá porque estavam no município do interior. Aí chegam lá: "Cadê o pessoal? Não, tão num município no interior..." (risos) (trabalhador-formador).

Em nossa inserção no campo da saúde alguns constrangimentos se anunciam em forma de precarização de contratos de trabalho, diferenciação valorativa do tipo de vínculo trabalhista dos profissionais (inclusive em um mesmo serviço), baixos salários que forçam a procura por mais uma fonte de renda. No entanto, os dados produzidos em nossa pesquisa atestam que esse jogo não se faz sem ruídos, sem resistência ativa, sem que os trabalhadores "burlem" as regras estritas e um curso pretensamente natural, 
até mesmo porque, como dizem Schawrtz e Durrive (2007), o trabalho restrito ao prescrito é um trabalho impossível, "invivível".

Os trabalhadores, frente aos constrangimentos, vão produzindo suas estratégias de enfrentamento e realizando suas atividades de modo a fazer perseverar o melhor que podem sua saúde, sua capacidade normativa. Neste percurso nos surpreendemos tanto com a violação da dignidade, enfraquecimento da potência da vida do trabalhador, quanto com os trajetos inusitados inventados atestando que a vida escapa e que busca produzir recursos para se afirmar. 0 trabalho, então, é tanto tecido em meio ao que se requisita de antemão como ao que se presentifica na experiência concreta do labor, forçando avaliação, decisões e escolhas por aquele que o vivencia.

Em consonância com Barros (2007), referenciando as produções de Schawrtz e Clot, temos que "o vital do humano não se resigna às condições dadas de trabalho" (p. 356), mas é preciso ter atenção e aprendizagem contínuas para perceber o que no meio do inferno não é inferno, fazendo-o então viver, produzindo espaço para que sua potência seja ampliada (Calvin, 2007). Como nos lembra Foucault (2006), se há relações de poder não é porque está tudo dominado, mas sim porque essas se dão em meio às práticas de liberdade. Acompanhamos, então, Passos (2009) na importância de estar atentos às formas do perigo e para as linhas de resistência: "Como se dão as resistências no contemporâneo?" (p. 19).

Os impasses na feitura de um trabalho de pesquisa, a imbricação de vida e pensamento fazem emergir como analisadores os impasses dos trabalhadores em seu cotidiano do fazer-saúde, os impasses de formadores em procurar realizar uma formação com a circulação da palavra, com a produção de autonomia e fortalecimento da transversalidade de uma política pública que se constitua ela mesma como obra aberta ${ }^{13}$.

A PNH como dispositivo de análise, dispositivo de dispositivos! Curso como produção de escuta de vozes que "cantam" diferentes entendimentos sobre o humano, a humanização, o cuidado humanizado e que oportuniza possíveis provisórios (problemas, soluções, caminhos, torções) e possíveis permanentes (conquistas trabalhistas), a construção de um comum sem o apagamento das singularidades. Um curso, enfim, em que a experimentação maior talvez tenha sido pensar e operar deslocamentos, ultrapassar queixas e construir outros movimentos em saúde, afirmando cotidianamente o vital do humano e a criação no trabalho.

\section{Colaboração dos autores}

As autoras contribuíram igualmente em todas as etapas da elaboração do artigo.

\section{Referências}

BARROS, M. E. B. Trabalhar: usar de si: sair de si. Interface: Comunicação, Saúde, Educação, Botucatu, v. 11, n. 22, p. 345-363, 2007.

BARROS, M. E. B.; BENEVIDES, R. Da dor ao prazer no trabalho. In: SANTOS-FILHO, S. B.; BARROS, M. E. B. (Org.). Trabalhador da saúde: muito prazer!: protagonismo dos trabalhadores na gestão do trabalho em saúde. Ijuí: Unijuí, 2007. p. 61-71.

BENEVIDES, R.; PASSOS, E. A humanização como dimensão pública das políticas de saúde. Ciência \& Saúde Coletiva, Rio de Janeiro, v. 10, n. 3, p. 561571,2005 .

BRASIL. Ministério da Saúde. Secretaria de Atenção à Saúde. Núcleo Técnico da Política Nacional de Humanização. HumanizaSUS: documento base para gestores e trabalhadores do SUS. 4. ed. Brasília, DF, 2008.

CAMPOS, G. W. S. Considerações sobre a arte e a ciência da mudança: revolução das coisas e reforma das pessoas. In: MERHY, E. E.; CAMPOS, G. W. S.; CECILIO, L. C. O. (Org.). Inventando a mudança na saúde. São Paulo: Hucitec, 1997. p. 29-88.

13 REDEHUMANIZASUS. A dor do parto porEduardo Passos. Vídeo. Disponível em: 〈http://www.youtube.com/watch?v=HAiPAAC4tHo\&NR=1>. Acesso em: 9 maio 2009. 
CAMPOS, G. W. S. Um método para análise e cogestão de coletivos. São Paulo: Hucitec, 2000.

DELEUZE, G. A intuição como método. In: Bergsonismo. São Paulo: Ed. 34, 1999. p. 7-26.

FONSECA, T. M. G.; BARROS, M. E. B. Entre prescrições e singularizações: o trabalho em vias da criação. Fractal: Revista de Psicologia, Rio de Janeiro, v. 22, n. 1, p. 101-114, 2010.

FOUCAULT, M. A vida: a experiência e a ciência. In: MOTTA, M. B. (Org.). Arqueologia das ciências e história dos sistemas de pensamento. Rio de Janeiro: Forense Universitária, 2005. p. 352-366. (Ditos e Escritos, II).

FOUCAULT, M. A ética do cuidado de si como prática da liberdade. In: MOTTA, M. B. (Org.). Ética, sexualidade, política. Rio de Janeiro: Forense Universitária, 2006. p. 264-287. (Ditos e Escritos, V).

GUATTARI, F.; ROLNIK, S. Subjetividade e história. In:___. Micropolítica: cartografias do desejo. Petrópolis: Vozes, 2005. p. 33-148.

HARDT, M.; NEGRI, A. Império. 7. ed. Rio de Janeiro: Record, 2005.

KIRST, P. G. et al. Conhecimento e cartografia: tempestade de possíveis. In: FONSECA, T. M. G.; KIRST, P. G. (Org.). Cartografias e devires: a construção do presente. Porto Alegre: UFRGS, 2003. p. 91-101.
LOURAU, R. Análise institucional e práticas de pesquisa. Rio de Janeiro: UERJ, 1993.

MERHY, E. E. Saúde: a cartografia do trabalho vivo. São Paulo: Hucitec, 2002.

MERHY, E. E. et al. Em busca de ferramentas analisadoras em saúde: a informação e o dia-a-dia de um serviço, interrogando e gerindo trabalho em saúde. In: MERHY, E. E.; ONOCKO, R. (Org.). Agir em saúde: um desafio para o público. 2. ed. São Paulo: Hucitec, 2002. p. 113-150.

PASCHE, D. F. Política nacional de humanização como aposta na produção coletiva de mudança nos modos de gerir e cuidar. Interface: Comunicação, Saúde, Educação, Botucatu, v. 13, p. 701-708, 2009. Suplemento 1.

PASSOS, E. Quando o grupo é afirmação de um paradoxo. In: BARROS, R. B. Grupo: a afirmação de um simulacro. 2. ed. Porto Alegre: Sulina: UFRGS, 2009. p. 11-23.

PASSOS, E.; BENEVIDES, R. B. Clínica, política e as modulações do capitalismo. Lugar Comum, Rio de Janeiro, v. 13, n. 19-20, p. 159-171, 2004.

REVEL, J. Michel Foucault: conceitos essenciais. São Carlos: Claraluz, 2005.

RODRIGUES, H. B. C. Análise institucional francesa e a transformação social: o tempo (e contratempo) das intervenções. In: RODRIGUES, H. B. C.; ALTOÉ, S. Análise institucional. São Paulo: Hucitec, 2004. p. 115-164. (Série Saúdeloucura, 8). 